\title{
Unexpected Presence of Neurofilaments in Axon-bearing Horizontal Cells of the Mammalian Retina
}

\author{
Leo Peichl' and Juncal González-Soriano² \\ ${ }^{1}$ Max-Planck-Institut für Hirnforschung, D-60528 Frankfurt/M., Germany and 2Departamento de Anatomia y Embriologia, \\ Facultad de Veterinaria, Universidad Complutense, E-28040 Madrid, Spain
}

\begin{abstract}
In several mammals only one of the two types of retinal horizontal cell, the axonless A-type, appears to express neurofilaments. Neurofilament immunostaining of rodent retinas reveals a horizontal cell plexus that has previously been interpreted as belonging to A-type cells. Our intracellular Lucifer yellow injections strongly suggest that there are no A-type horizontal ceils in rat and gerbil. Counterstaining of dye-injected cellular structures with a neurofilament antibody directly shows that the axon terminal systems of the axon-bearing B-type horizontal cells contain neurofilaments. These unexpected findings explain and reinterpret the neurofilament plexus in rodent retinas. In contrast, Lucifer yellow injections in guinea pig retina reveal both A- and B-type horizontal cells, showing that horizontal cell types are not uniform among rodents. In the guinea pig retina both A-type cells and B-type axon terminal systems contain neurofilaments.
\end{abstract}

[Key words: rodent retina, horizontal cells, neurofilaments, rat retina, guinea pig retina, Lucifer yellow]

Neurofilaments are neuron-specific members of the intermediate-filament family of cytoskeletal proteins. Their structure and function as neurofibrils were a hotly debated issue in the controversies about the "neuron doctrine" at the turn of the century (see, e.g., Ramón y Cajal, 1908). More recently, intensive research on the structure, localization, and possible function of neurofilaments relies on immunocytochemical and molecular biological methods (for reviews, see, e.g., Shaw, 1986, 1991; Matus, 1988; Fliegner and Liem, 1991).

The vertebrate retina is a clearly structured part of the CNS where well-defined cell types are easily identified, and the retinas of readily available laboratory rodents have often been used to study the localization of neurofilaments in defincd ncuron types. It has been shown that horizontal cell processes in the outer plexiform layer of rodent retinas are reactive to antibodies against neurofilaments (Dräger, 1983, 1985; Shaw and Weber, 1983, 1984; Weber et al., 1983; Dräger et al., 1984; Dahl and Bignami,

\footnotetext{
Received Nov. 13, 1992; revised Apr. 5, 1993; accepted Apr. 13, 1993.

We thank Dr. Brigitte Müller for fruitful discussions and important suggestions and acknowledge her, Dr. Ulrike Grünert's, and Ralf Engelmann's advice on immunostaining. We also thank Prof. Brian Boycott, Dr. Jutta Schnitzer, and Dr. Gerry Shaw for helpful discussions and comments on the manuscript. Dr. G. Shaw kindly provided some of the antibodies. Heide Ahmed's skilled technical assistance is gratefully acknowledged. J.G.-S. received a joint fellowship by the D.G.I.C.Y.T., Spain, and the Max-Planck-Gesellschaft, Germany.

Correspondence should be addressed to Dr. Leo Peichl, Max-Planck-Institut. für Hirnforschung, Deutschordenstrasse 46, D-60528 Frankfurt/M., Germany.

Copyright (C) 1993 Society for Neuroscience $0270-6474 / 93 / 134091-10 \$ 05.00 / 0$
}

1991; Hammang et al., 1992; Vickers and Costa, 1992). However, to date there has been no detailed morphological description of rodent horizontal cells, and it remains unproven which types of horizontal cells and which parts of individual cells are actually labeled by the antibodies. We have now studied the morphology of rodent horizontal cells and directly determined which structures in the outer plexiform layer are neurofilament (NF) immunoreactive.

Horizontal cells are interneurons that modulate the information transfer from the photoreceptors to the bipolar cells in the outer plexiform layer. Studies in various nonrodent species have established that mammalian retinas generally contain two types of horizontal cell (reviewed, e.g., in Ramón y Cajal, 1893; Gallego, 1983, 1986; Boycott et al., 1987), commonly termed "axonless horizontal cell" or A-type and "short axon horizontal cell" or B-type now. The B-type has a smaller dendritic tree formed by many relatively fine dendrites, and an axon that ends in a profuse axon terminal system. Dendrites makc synaptic contacts exclusively with cones; the axon terminal system, exclusively with rods (Kolb, 1974; Linberg and Fisher, 1988). The A-type horizontal cell has a larger, more sparsely branched dendritic tree with fewer and stouter primary dendrites and makes synaptic contacts exclusively with cones. It has no axon.

A further characteristic of the axonless A-type cells in several mammals is the high content of neurofilaments in their cytoskeleton (Fisher and Boycott, 1974), which is reflected in their selective stainability with classical neurofibrillar methods (reviewed, e.g., in Wässle et al., 1978; Dräger et al., 1984). Using this evidence from nonrodent mammals, Dräger (1983) interpreted the NF-immunoreactive plexus in mouse and rat outer plexiform layer as similarly indicating the presence of A-type horizontal cells; most subsequent studies have adopted this interpretation.

We studied the morphology of rodent horizontal cells with intracellular injections of the fluorescent dye Lucifer yellow (LY). We found typical A- and B-type horizontal cells in the guinea pig, but only B-type cells in the rat and gerbil. Further evidence for this rodent peculiarity will be the subject of a separate report (L. Peichl and J. González-Soriano, unpublished observations), but some of the results are briefly reported here, because they raise the question of what, if not A-type horizontal cells, are the structures that are revealed by NF antibodies in the outer plexiform layer of rodent retinas. To address this question directly, we localized NF immunoreactivity in identified cellular components. An unexpected result is that the axon terminal systems of B-type horizontal cells also contain neurofilaments. This challenges some of the findings and interpretations reported above, and offers an assay to study cell biological and molecular aspects of the NF proteins. 


\section{Materials and Methods}

\section{Animals}

Adult rats, mice, gerbils, and guinea pigs were used. Among the rats and mice there were albinos (mixed breeds) and natural-colored breeds; guinea pigs were multicolored or of the Pirbright White albino strain, and gerbils were natural colored. No breed differences were observed in our results. Animals were killed by an overdose of halothane. The eyes were enucleated directly post-mortem, partially opened behind the cornea, and immersion fixed. After $30 \mathrm{~min}$ the anterior part of the eye with the lens was completely removed and the eyecup with the retina returned to the fixative.

\section{Lucifer yellow injections}

For I ucifer yellow (LY) injections the fixative was $2 \%$ paraformaldehyde in $0.1 \mathrm{M}$ phosphate buffer $(\mathrm{PB} ; \mathrm{pH} 7.4)$ and total fixation time was $1 \mathrm{hr}$ at room temperature; the eyecup was then transferred to PB. The vitreous was cut away as far as possible without putting mechanical stress on the retina, and the retina was carefully isolated and spread flat in a Petri dish containing PB. The dish was placed under a fixed-stage epifluorescence microscope for LY injections. A detailed description of the procedure is given in Peichl et al. (1987); it follows the protocol of Tauchi and Masland (1984).

Briefly, a micropipette containing a $5 \%$ aqueous solution of $L Y$ was advanced through the retinal layers under visual control, until short test ejections of LY indicated that the outer border of the inner nuclear layer was reached. Somata, or processes in the outer plexiform layer, were impaled and LY applied iontophoretically by a constant negative current of 1-4 nA. When, the impaled cell was a horizontal cell, dye injection was continued for up to $20 \mathrm{~min}$ until no further spread of the LY occurred or the LY leaked out of the cell. Many fills did not reveal complete cells, and only cells where at least a major part of the processes was visualized were included in the study. These were about 40 cells in five rat retinas, about 20 cells in two gerbil retinas, and about 100 cells in three guinea pig retinas.

Injected retinas were postfixed for $1 \mathrm{hr}$ in the same fixative. Some were then subjected to immunocytochemical staining (see below). The others were mounted on a slide in a mixture of $90 \%$ glycerol in phosphate-buffered saline with $2.5 \%$ potassium iodide, and coverslipped. LY-filled cells were photographed in flat view with Zeiss Neofluar objectives and high-speed film. Drawings of cells were made from projected negatives.

\section{Neurofilament immunostaining}

Antibodies. A commercially available mouse monoclonal antibody raised against human neurofilament (clone 2F1 1; no. MON 3004, Sanbio) was used in most experiments because its staining was most robust. It specifically recognizes the $70 \mathrm{kDa}$ (NF-L) and $200 \mathrm{kDa}$ (NF-H) subunits of neurofilament and shows no detectable cross-reactivity with glial fibrillary acidic protein, vimentin, desmin, and keratin. To assess whether the three neurofilament subunits NF-L, NF-M (160 kDa), and NF-H are expressed differently in rodent horizontal cells, additional experiments were done with mouse monoclonal antibodies specifically recognizing NF-L (clones NR4 and DA2), NF-M (clones NN18 and 3H11), NF-H (clones NE14 and N52), and phosphorylated NF-M/H (clone NAP4). Antibodies NR4, NN18, NE14, and N52 were purchased from Sigma; antibodies DA2, 3H 11 , and NAP4 were kindly provided by Dr. G. Shaw (University of Florida). The antibodies are described in Shaw et al. (1986) and Harris et al. (1991).

Tissue preparation. For immunostaining, rat, mouse, gerbil and guinea pig eyes were fixed in $4 \%$ paraformaldehyde in $\mathrm{PB}$ at $4^{\circ} \mathrm{C}$ for $3-4 \mathrm{hr}$ (2F11) or $1 \mathrm{hr}$ (other antibodies) as described above. Retinas were then isolated, rinsed in PB for several hours, and cryoprotected by successive immersion in $10 \%, 20 \%$, and $30 \%$ sucrose in PB. Retinas to be stained in toto were then repeatedly shock frozen and thawed in liquid nitrogen to improve penetration of the antibodies. Other retinas were frozen flat onto a block of tissue freezing medium (Reichert-Jung) and $40 \mu \mathrm{m}$ sections parallel to the retinal layers (horizontal sections) were cut on a freezing microtome. LY-injected retinal pieces were also shock frozen and immunostained as a whole. Both whole retinas and horizontal sections were reacted free floating.

Immunostaining. Tissue was preincubated in $\mathrm{PB}$ with $10 \%$ normal goat serum, $1 \%$ bovine serum albumin, and $1 \%$ Triton X-100 for $1 \mathrm{hr}$ at room temperature and then transferred to the primary antibody solution. For whole retinas and horizontal sections, the antibodies were diluted 1:10 (2F11), 1:50 (NN18), 1:200 (N52), or 1:500 (DA2, 3H11, NAP4) in a medium containing $3 \%$ normal goat scrum, $0.5 \%$ Triton $\mathrm{X}-100$, and $0.01 \%$ sodium azide in $\mathrm{PB}$. Incubation time was $2 \mathrm{~d}$ at room temperature or $4-5 \mathrm{~d}$ at $4^{\circ} \mathrm{C}$. After several rinses in $\mathrm{PB}$, the tissue was incubated in biotinylated goat anti-mouse IgG (Sigma B-7265), diluted $1: 50$ in $\mathrm{PB}$ with $0.5 \%$ Triton $\mathrm{X}-100$, for $16 \mathrm{hr}$ at room temperature. The tissue was washed, and then incubated in Extravidin peroxidase conjugate (Sigma E-2886), diluted 1:100 in PB, for $1 \mathrm{~d}$ at room temperature. The peroxidase was visualized by incubating the tissue in $0.05 \%$ diaminobenzidine (DAB) in PB for $10 \mathrm{~min}$ and then adding $0.01 \%$ hydrogen peroxide to start the reaction, which sufficiently developed within 5-10 min. The tissue was then washed and postfixed for $1 \mathrm{hr}$ in the initial fixative before mounting. Horizontal sections yielded a more intense immunostaining than whole retinas, and all micrographs of DAB-reacted tissue are from sections. Control staining, where the primary antibody was omitted in the first incubation solution, showed no neuronal labeling.

For each species, additional transverse sections through the retina (vertical $15 \mu \mathrm{m}$ cryostat sections) were immunoreacted with the $\mathrm{NF}$ antibodies. Staining was on the slide, and the antibodies and dilutions used are listed in Table 1. Antibodies were diluted in the above medium and incubation time was overnight at room temperature. Incubation in the goat anti-mouse antibody and the Extravidin peroxidase conjugate was at the above dilutions for $1 \mathrm{hr}$ at room temperature, and visualization was with DAB.

For the counterstaining of LY-injected tissue, antibody $2 \mathrm{~F} 11$ was visualized by immunofluorescence. For this, the third incubation step was in Texas red-streptavidin (Amersham RPN.1233), diluted 1:100 in $\mathrm{PB}$, for 2-3 $\mathrm{hr}$ at room temperature. The tissue was then washed and postfixed as above.

\section{Results}

To identify which horizontal cells, and which parts of them, are labeled by NF antibodies, a three-step approach was adopted: (1) morphological characterization by dye injection of the horizontal cells that are present in rodent retinas, (2) immunocytochemical labeling of NF-containing structures in the outer plexiform layer to assess their detailed appearance and possible identity, and (3) a combination of dye injection and subsequent NF labeling to demonstrate neurofilaments in identified processes.

\section{Morphology of rodent horizontal cells}

To stain individual horizontal cells, fixed retinas of rat, gerbil, and guinea pig were injected with the fluorescent dye LY. The injection pipette was advanced through the retinal layers to the outer border of the inner nuclear layer, or to the outer plexiform layer, where the somata and processes, respectively, of the horizontal cells are located. Then LY was applied iontophoretically, and when a horizontal cell was impaled, LY injection was continued until the dye had spread as far as possible within the processes of the cell (Fig. 1).

Guinea pig. In the guinea pig two types of horizontal cell were found (Fig. 2). Their dendritic morphologies closely resemble those of the A- and B-type cells of other mammals. The A-type is larger, less densely branched with stouter dendrites, and we never found an axon on it. The smaller B-type has more and finer dendrites and an axon. The dendrites of both types are studded with spinelike terminals, which are the sites of photoreceptor contacts. When a B-type soma or dendrite is injected, only a small amount of the dye travels along the fine axon and usually does not reveal much detail of the axon terminal system at the end of the axon. In many cases the dye only travels along part of the axon and does not even reach the terminal system.

To assess the detailed morphology of axon terminal systems, they had to be injected directly. Then a rich arborization is revealed, which consists of irregularly curved main branches 
Table 1. Neurofilament immunoreactivity in rodent retinas as seen in vertical sections

\begin{tabular}{|c|c|c|c|c|c|c|c|c|c|}
\hline \multirow[b]{2}{*}{ Species } & \multirow[b]{2}{*}{ Structure } & \multicolumn{8}{|c|}{ Clone (antibody number) (NF reactivity, dilution used) } \\
\hline & & $\begin{array}{l}\text { NR4 } \\
(\mathrm{NF}-\mathrm{L} \mathrm{pi}, \\
1: 100)\end{array}$ & $\begin{array}{l}\text { DA2 } \\
\text { (NF-L, } \\
1: 500)\end{array}$ & $\begin{array}{l}\text { NN18 } \\
(\text { NF-M pi, } \\
1: 40)\end{array}$ & $\begin{array}{l}3 \mathrm{H} 1 \mathrm{l} \\
\text { (NF-M pi, } \\
1: 500)\end{array}$ & $\begin{array}{l}\text { NE14 } \\
(\mathrm{NF}-\mathrm{H} \mathrm{pd}, \\
1: 500) \\
\end{array}$ & $\begin{array}{l}\text { N52 } \\
\text { (NF-H pi, } \\
1: 200)\end{array}$ & $\begin{array}{l}2 \mathrm{~F} 11 \\
(\mathrm{NF}-\mathrm{L} / \mathrm{H}, \\
1: 10)\end{array}$ & $\begin{array}{l}\text { NAP4 } \\
\text { (NF-M/H pd, } \\
1: 1000)\end{array}$ \\
\hline \multirow[t]{5}{*}{ Rat } & OPL he plexus & + & +++ & $+/++$ & ++ & +++ & +++ & +++ & ++ \\
\hline & Hc somata & - & - & - & - & - & + & - & - \\
\hline & Bipolar cells & - & - & - & - & - & - & - & - \\
\hline & IPL & +++ & +++ & $+/++$ & ++ & + & ++ & + & ++ \\
\hline & ONFL & +++ & +++ & +++ & +++ & +++ & +++ & +++ & +++ \\
\hline \multirow[t]{5}{*}{ Mouse } & OPL he plexus & ++ & +++ & +++ & +++ & $++t$ & ++ & +++ & +++ \\
\hline & Hc somata & - & - & - & - & - & - & - & - \\
\hline & Bipolar cells & - & - & - & - & - & - & - & - \\
\hline & IPL & ++ & ++ & + & + & + & ++ & + & ++ \\
\hline & ONFL & +++ & +++ & +++ & +++ & +++ & +++ & +++ & +++ \\
\hline \multirow[t]{5}{*}{ Gerbil } & OPL hc plexus & - & ++ & +++ & +++ & $+++/+^{a}$ & $+++1+^{a}$ & +++ & $+++/+^{a}$ \\
\hline & Hc somata & - & - & - & - & - & - & - & - \\
\hline & Bipolar cells & - & - & - & - & - & - & - & - \\
\hline & IPL & ++ & ++ & ++ & + & ++ & ++ & ++ & ++ \\
\hline & ONFL & +++ & ++ & +++ & +++ & +++ & +++ & +++ & +++ \\
\hline \multirow{5}{*}{ Guinea pig } & OPL he plcxus & $+++/+a$ & $+++1+^{a}$ & $++/+^{a}$ & $++/-a$ & +++ & +++ & $+++/++a$ & +++ \\
\hline & Hc somata & $+++/+^{a}$ & $+++1+^{a}$ & $++/-a$ & $++1-a$ & +++ & +++ & $+++1-a$ & $+++1++$ \\
\hline & Bipolar cells & ++ & + & ++ & ++ & - & - & - & ++ \\
\hline & IPL & ++ & ++ & ++ & + & ++ & ++ & ++ & ++ \\
\hline & ONFL & +++ & +++ & +++ & +++ & +++ & +++ & +++ & +++ \\
\hline
\end{tabular}

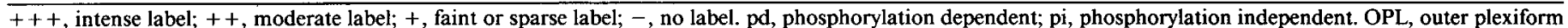

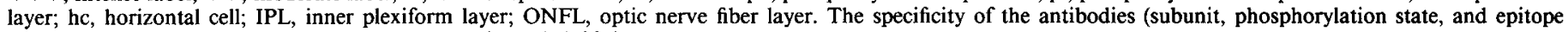
recognized) is given in Shaw et al. (1986) and Harris et al. (1991).

${ }^{a}$ Regional difference in labeled structures.

and many fine side branches, which again carry spinelike synaptic terminals. The axon terminal system is connected to its parent soma by a fine axon. In some cases the dye spread back to the soma and revealed enough of the dendritic morphology to identify the cell as B-type. More commonly, only a section of the fine axon was filled when a terminal system was injected. However, the presence of axons on B-type cells and on axon terminal systems, but not on A-type cells, is strong evidence that all axon terminal systems belong to B-type cells.

Rat and gerbil. In the rat and gerbil, only one type of horizontal cell was found, which resembles the B-type cell of other mammals (Figs. $1 A, B, 2$ ). The cells have a relatively densely branched dendritic tree and an axon ending in an axon terminal system. In a sample of some 40 rat cells and some 20 gerbil cells, we did not find individuals with an A-type morphology. In guinea pig the encounter rate of A-and B-type cells was about equal, indicating that the observed absence of A-type cells in our rat and gerbil sample is not an artifact due to a sampling bias for B-type cells. As in guinea pig, injections into rat and gerbil horizontal cell somata usually only revealed part of the axon or an understained axon terminal system. Hence, direct injections of axon terminal systems were used to assess their detailed morphology (Fig. $1 B$ ).

\section{NF immunocytochemistry}

It is generally assumed that among horizontal cells only the A-type is revealed by classical neurofibrillar stains or NF antibodies (Wässle et al., 1978; Dräger et al., 1984). With the above findings it was all the more interesting to see what NF antibodies actually label in the rodent outer plexiform layer. We mainly used the antibody $2 \mathrm{~F} 11$, which specifically recognizes the NF-L and NF-H subunits of the NF triplet. For rat, gerbil, mouse, and guinea pig, we stained unsectioned retinas or $40 \mu \mathrm{m}$ horizontal sections that contained the outer plexiform layer. Additional vertical sections show the layered structure of the retina and an intense NF-immunoreactive band in the outer plexiform layer, confirming the presence of neurofilaments in that layer (Fig. 3A, Table 1).

Rat, gerbil, and mouse. In rat, gerbil, and mouse, the outer plexiform layer contains a rather dense irregular plexus of NFimmunoreactive processes, which is best seen in horizontal sections (Fig. 3B-D). The density of the plexus and the diameters of the processes vary somewhat between species, and also with location on the retina. The complete extent of single processes in the plexus cannot be followed. It is clear, however, that no somata are labeled, and that the plexus does not contain proccsscs that cmcrge radially in a starlike fashion from possibly unstained somata, in which case they could have been readily identified as dendritic trees. From this material it appears that no somata and dendrites of horizontal cells are NF immunoreactive. Thus, the plexus probably consists of $\mathrm{B}$-type axon terminal systems; the main branches of LY-filled axon terminal systems (Fig. 2) resemble the curved processes seen in Figure $3 B-D$. This conjecture is confirmed below. Bipolar cell dendritic trees, which also occupy the outer plexiform layer, are not labeled with NF antibodies (see Table 1). They would be much smaller and could not be confused with the present plexus.

Guinea pig. In guinea pig the staining is very different. Over most of the retina, somata and radially extending dendrites are labeled in the outer plexiform layer and adjacent inner nuclear layer (Fig. 3E). Tracing of individual cells indicates that they are A-type horizontal cells. However, the plexus is denser than 

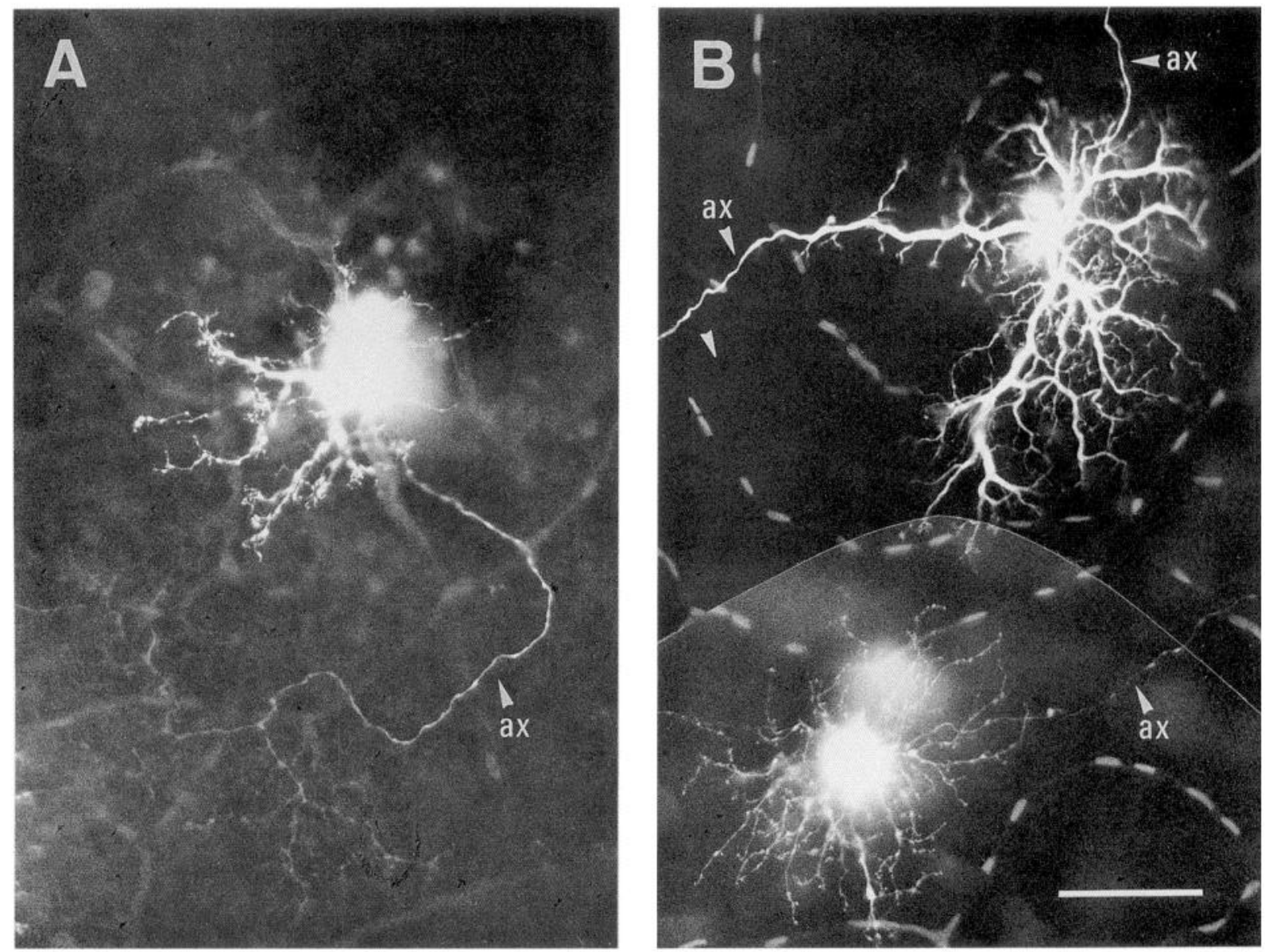

Figure 1. LY-injected horizontal cells in rodent retinas. The micrographs show flat views, focused on the outer plexiform layer in whole-mounted retinas. $A$, Rat B-type horizontal cell injected at the soma. The dendritic tree (top) is probably not completely revealed but many spinelike dendritic terminals are visible. The axon $(a x)$ ends in a branched axon terminal system (bottom) that is only faintly stained. $B$, Gerbil B-type dendritic tree (bottom) with a faint axon, and two overlapping axon terminal systems (top) stained by successive impalement: montage of two micrographs with focus on the dendrites and axon terminal processes, respectively (synaptic terminals of the axon terminal systems are out of focus). The injection sites are recognized by LY deposits that have diffused into extracellular space. The capillary bed in the outer plexiform layer also fluoresces. Scale bar, $50 \mu \mathrm{m}$.

would be expected if only the A-type cells were labeled. This suggests that there are additional NF-containing elements, which is confirmed by the experiments described below.

In a restricted region of the guinea pig retina, the A-type somata and dendrites are not revealed by the antibody $2 \mathrm{~F} 11$. Here the plexus is devoid of somata and shows the same characteristics as that of rat, gerbil, and mouse (Fig. $3 F$ ). The region extends as a horizontal band from temporal periphery to nasal midperiphery just superior to the optic nerve head. The same feature is revealed by some of the other antibodies (see below and Table 1).

\section{NF labeling of identified structures}

A combination of $\mathrm{LY}$ injection and $2 \mathrm{~F} 11$ immunolabeling was applied in rat, gerbil, and guinea pig retina (Fig. 4). First, several horizontal cell dendritic trees and axon terminal systems were dye injected. Then the retinal pieces were run through the antibody staining procedure, and Texas red-avidin was used to visualize the immunolabeling. Here less LY was injected than in the previous experiments in order not to mask binding sites or the visualization of the NF antibody. Fortunately, it turned out that LY did not mask the antigenic sites of neurofilaments and that the double staining procedure was feasible. This is not a matter of course since LY was, for example, incompatible with immunostaining for intracellular ChAT (Voigt, 1986). The LY did not fluoresce under the Texas red filter setting, as evidenced in Figure $4, B$ and $D$. Texas red only very faintly fluoresced under the LY filter setting (Fig. $4 C$ ), so no identification problems arose.

In all three species, rat, gerbil, and guinea pig, identified B-type axon terminal systems proved to be NF immunoreactive. This is illustrated for the gerbil in Figure 4, $A$ and $B$, and for the guinea pig in Figure 4, $C$ and $D$. The neurofilaments appear mostly restricted to the larger-caliber processes of the axon terminal system and the intricate pattern of the fine branches is not seen (compare Fig. 2). However, in several cases the fine axon was also labeled, as in Figure $4 D$. The majority of LYinjected axon terminal systems were NF immunoreactive, but in a few, no NF label was found. It is unclear whether this was a technical problem of staining intensity and detection, or whether there is a subpopulation of axon terminal systems that is not recognized by the antibody.

The dendritic trees of all LY-injected horizontal cells in rat and gerbil, and of the B-type cells in guinea pig, were not immunoreactive to $2 \mathrm{~F} 11$. Injected A-type cells of the guinea pig were immunoreactive in those regions of the retina where soma 
GUINEA PIG

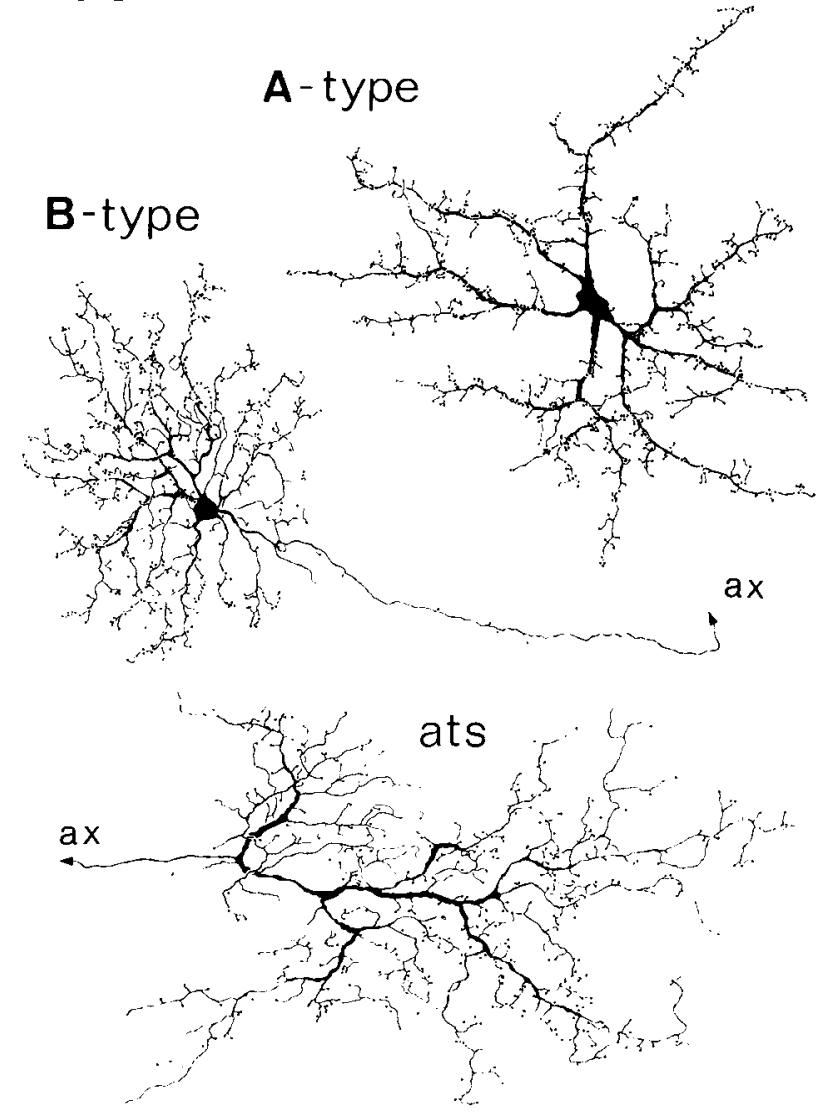

RAT

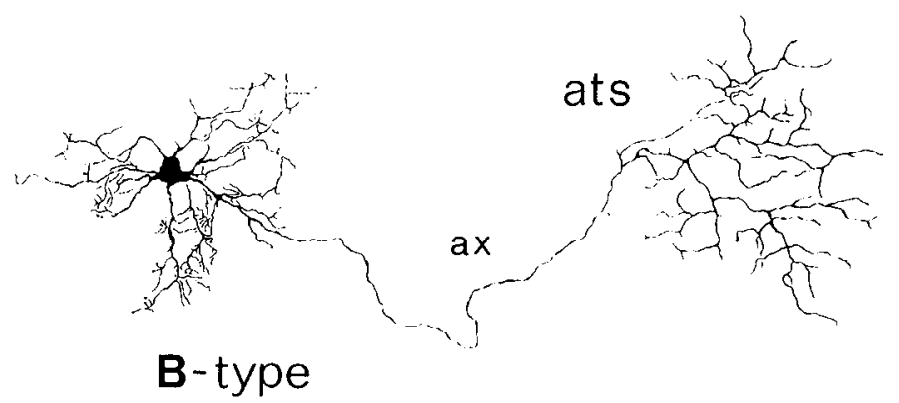

\section{GERBIL}

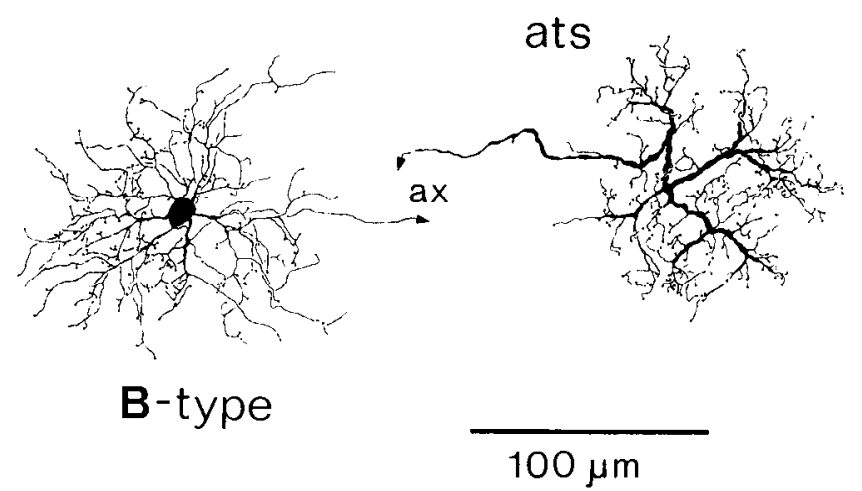

Figure 2. Drawings of LY-injected horizontal cells. In guinea pig (left) A- and B-type cells exist. The B-type has an axon (ax); the A-type is axonless. The axon terminal system (ats) belongs to another B-type cell. In rat and gerbil (right) only B-type cells with axon and axon terminal system were found. All cells are drawn at the same scale.

staining was present (compare Fig. $3 E$ ), but were not immunoreactive in regions where only the plexus stained (compare Fig. $3 F$ ). This set of experiments shows directly that in rat and gerbil the NF-immunoreactive plexus in the outer plexiform layer consists of B-type axon terminal systems, whereas in guinea pig the NF-immunoreactive structures are A-type cells and B-type axon terminal systems.

\section{Localization of NF subunits}

Are all three subunits of the NF triplet expressed similarly in rodent horizontal cells? In all four species, immunostaining of vertical sections with a panel of subunit-specific antibodies shows that the horizontal cell plexus in the outer plexiform layer expresses all three NF subunits. The results are summarized in Table 1. For comparison, the staining pattern of selected other retinal structures is also listed. In rat, mouse, and gerbil, the structure of the horizontal cell plexus looks basically similar for all subunits, and horizontal cell somata are not labeled (with the exception of N52 label in rat). Staining of horizontal sections with selected subunit-specific antibodies confirms that all three NF subunits are present in the axon terminal systems of B-type horizontal cells. In the guinea pig retina, all three NF subunits are present in A-type horizontal cells (including the somata), and in B-type axon terminal systems.

In the vertical sections there are differences of labeling inten- sity between antibodies and species; for example, antibody NR4 is a poor marker of the NF-L subunit in gerbil and rat. The differences are not artifacts of processing, because other structures are intensely labeled in the same sections. In the thicker horizontal sections and in whole retinas, however, there are penetration problems for some of the antibodies. Differences in NF subunit expression depend on species, cellular compartment, and location on the retina. Inspection of vertical and horizontal sections establishes that in rat, but not in mouse and gerbil, the somata and dendrites of B-type horizontal cells are faintly $\mathrm{N} 52$ positive in addition to the strongly immunoreactive axon terminal systems (Table 1). Similarly, N52 faintly labels B-type somata and dendrites in guinea pig. None of the other antibodies shows such labeling.

In guinea pig, the NF-L and NF-M antibodies show a regional gradient of horizontal cell labeling with more intense staining in peripheral retina, which is not seen with the NF-H antibodies (Tablc 1). In unsectioned guinea pig retinas, antibodies DA2 and NAP4 had the same regional preference for A-type staining versus $B$-type axon terminal staining as antibody $2 \mathrm{~F} 11$ (see above and Fig. $3 E, F$ ). A regional gradient is also found in gerbil retina, where the horizontal cell plexus is strongly labeled by the NF-H antibodies in peripheral retina, but weakly labeled in central retina. In guinea pig, some of the antibodies stain a subset of bipolar cells, confirming previous reports (Shaw and Weber, 1984; Vickers and Costa, 1992). 

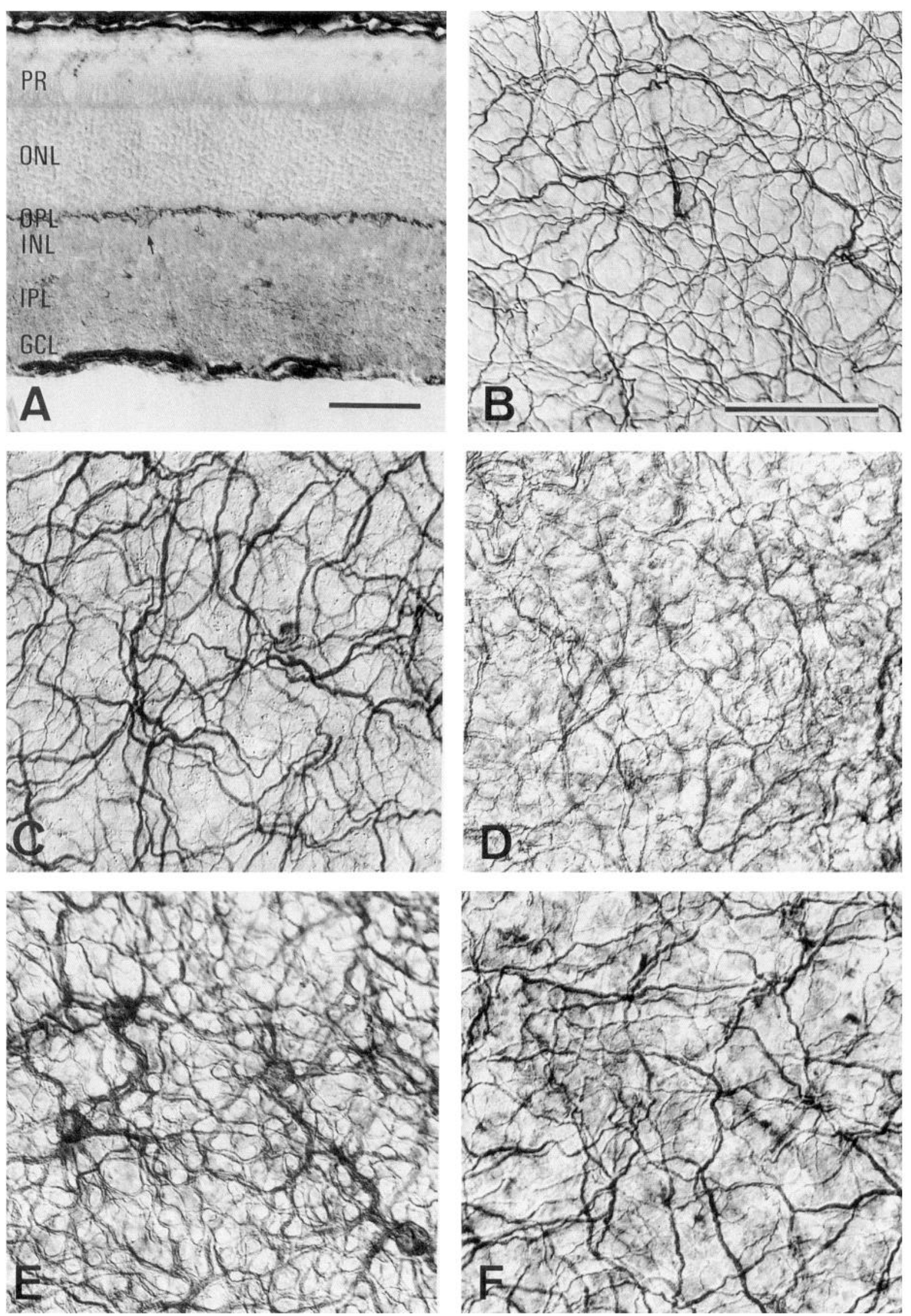


\section{Discussion}

\section{Is there only one type of horizontal cell in rodents?}

Rodents have been used in several studies to assess the retinal neuron types that are labeled by various antibodies to NF proteins, and horizontal cells were identified as an intensely immunorcactive neuron population (Dräger, 1983; Shaw and Weber, 1983, 1984; Weber et al., 1983; Dräger et al., 1984; Dahl and Bignami, 1991; Vickers and Costa, 1992). In rabbit and cat only one of the two horizontal cell types, the axonless A-type, contains large amounts of neurofilaments (Fisher and Boycott, 1974). As a detailed morphological description and classification of rodent horizontal cells did not exist, it was inferred that NF labeling indicated the presence of A-type horizontal cells also in rodents (Dräger, 1983, 1985; Dräger et al., 1984; Dahl and Bignami, 1991; Hammang et al., 1992).

To the contrary, our results show that the NF-containing plexus in rat and gerbil consists of B-type axon terminal systems, and indicate that in these species there are no axonless A-type horizontal cells. In contrast, guinea pigs have neurofibrillar A-type horizontal cells (Vickers and Costa, 1992; present results). Further evidence for only one type of horizontal cell in rat, gerbil, and mouse, and a discussion of rodent horizontal cell classification, will be given in a separate report (Peichl and GonzálezSoriano, unpublished observations). Suzuki and Pinto (1986) also only found axon-bearing B-type cells when they recorded and LY injected mouse horizontal cells. Similarly, only B-type horizontal cells are found in HRP-injected retinas of chestnut mouse (A. Harman, personal communication) and in Golgistained retinas of rat (V. H. Perry, personal communication).

It is strange that these rodents have only B-type cells whereas the guinea pig has A- and B-type cells like mammals outside the rodent order. Interestingly, the capybara and agouti (members of the rodent suborder Caviomorpha like the guinea pig) also have neurofibrillar A-type horizontal cells (Silveira et al., 1989; Yamada et al., 1992), and Mariani (1985) found A- and B-type horizontal cells in Golgi-stained red squirrel retina (suborder Sciumorpha). A lack of A-type horizontal cells thus appears to be a feature of some, but not all, rodent families (Peichl and González-Soriano, unpublished observations).

The functional consequences of having only one type of horizontal cell are difficult to judge because the detailed tasks of the horizontal cell types in mammalian visual information processing are not known (cf. Wässle and Boycott, 1991). A- and B-type horizontal cells of the rabbit retina have different dendritic field sizes and area summation characteristics (Bloomfield and Miller, 1982), but other response properties show no correlation with cell shape (Raviola and Dacheux, 1983); rabbit horizontal cells contribute to the receptive field surround of ganglion cells (Mangel, 1991). Sterling et al. (1986) have hypothesized that cat A- and B-type horizontal cells contribute antagonistically to the receptive field organization of retinal ganglion cells, but rats and mice have ganglion cells with cat- like center/surround antagonism (Partridge and Brown, 1970; Balkema and Pinto, 1982) despite the lack of A-type horizontal cells.

\section{Horizontal cell axon terminal systems contain neurofilaments}

We have provided dircet cvidence that the axon terminal systems of rodent B-type horizontal cells contain all three NF subunits. The plexus seen in our material resembles the NF-immunoreactive plexus previously described in mouse retina (Dräger, 1983; Dräger et al., 1984). Given the assumed selectivity of neurofibrillar stains for A-type horizontal cells in various mammals (see introductory remarks), it is easy to see how a misinterpretation of this plexus as A-type staining could come about. Dräger $(1983,1985)$ illustrates some isolated elements drawn from the plexus, and they have in fact a certain resemblance to A-type cells of other species. In our LY material some of the axon terminal systems also have main processes that resemble A-type dendritic trees; the gerbil axon terminal system of Figure 2, for example, could be mistaken for an A-type cell had the thin axon not stained. In the NF-immunolabeled material the stouter processes of the axon terminal systems dominate the plexus and thc defining axon is often not visible. Dräger's studies are the only ones that have used horizontal sections. Other authors (Dahl and Bignami, 1991; Hammang et al., 1992) used vertical sections, where horizontal cell morphologies are difficult to judge.

The present results stress the importance of detailed morphological information for the interpretation of immunocytochemical labeling. Our unexpected finding explains the plexus of NF-immunoreactive processes in the outer plexiform layer of rodents, and it challenges the notion, deduced from obscrvations with classical neurofibrillar stains and with electron microscopy, that among mammalian horizontal cells only the axonless A-type contains neurofilaments. In rodents the problem was particularly obvious when the LY injections indicated an absence of A-type cells. In mammals that have NF-immunoreactive A-type cells (like the guinea pig), additional NF-containing axon terminals might go unnoticed in the plexus (cf. Vickers and Costa, 1992). We since found that rabbit B-type axon terminal systems also contain neurofilaments (S. Löhrke, J. H. Brandstätter, and L. Peichl, unpublished observations), and studies in further species should clarify whether B-type axon terminal systems are generally NF containing in mammalian retinas. Interestingly, Gallego $(1976,1983)$ mentioned a horizontal cell axon terminal plexus containing neurofibrils in the retinas of turtles and diurnal birds and at that time stressed this as a difference from mammals.

\section{NF subunits in distinct cellular compartments}

Our observations contribute to the cell biological question of differential distributions of NF subunits within neurons. Guinea pig A-type horizontal cells contain all three NF subunits in their

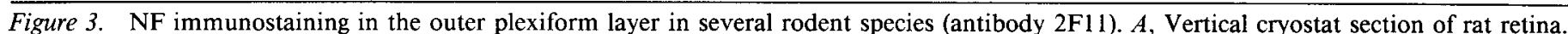

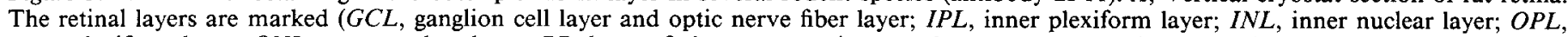

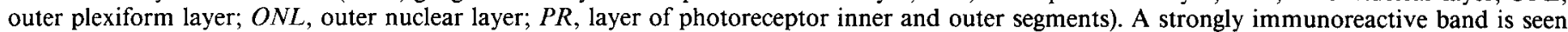

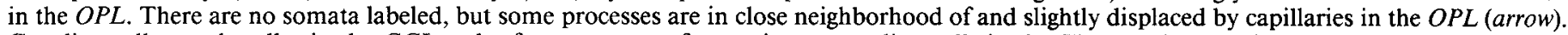

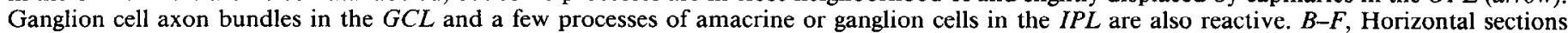

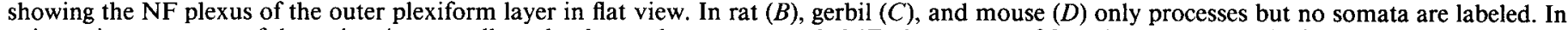

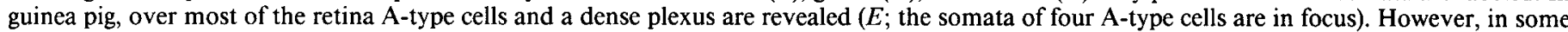

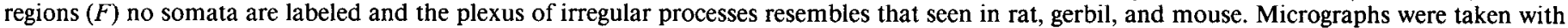
Nomarski optics. Scale bars, $50 \mu \mathrm{m}$. 

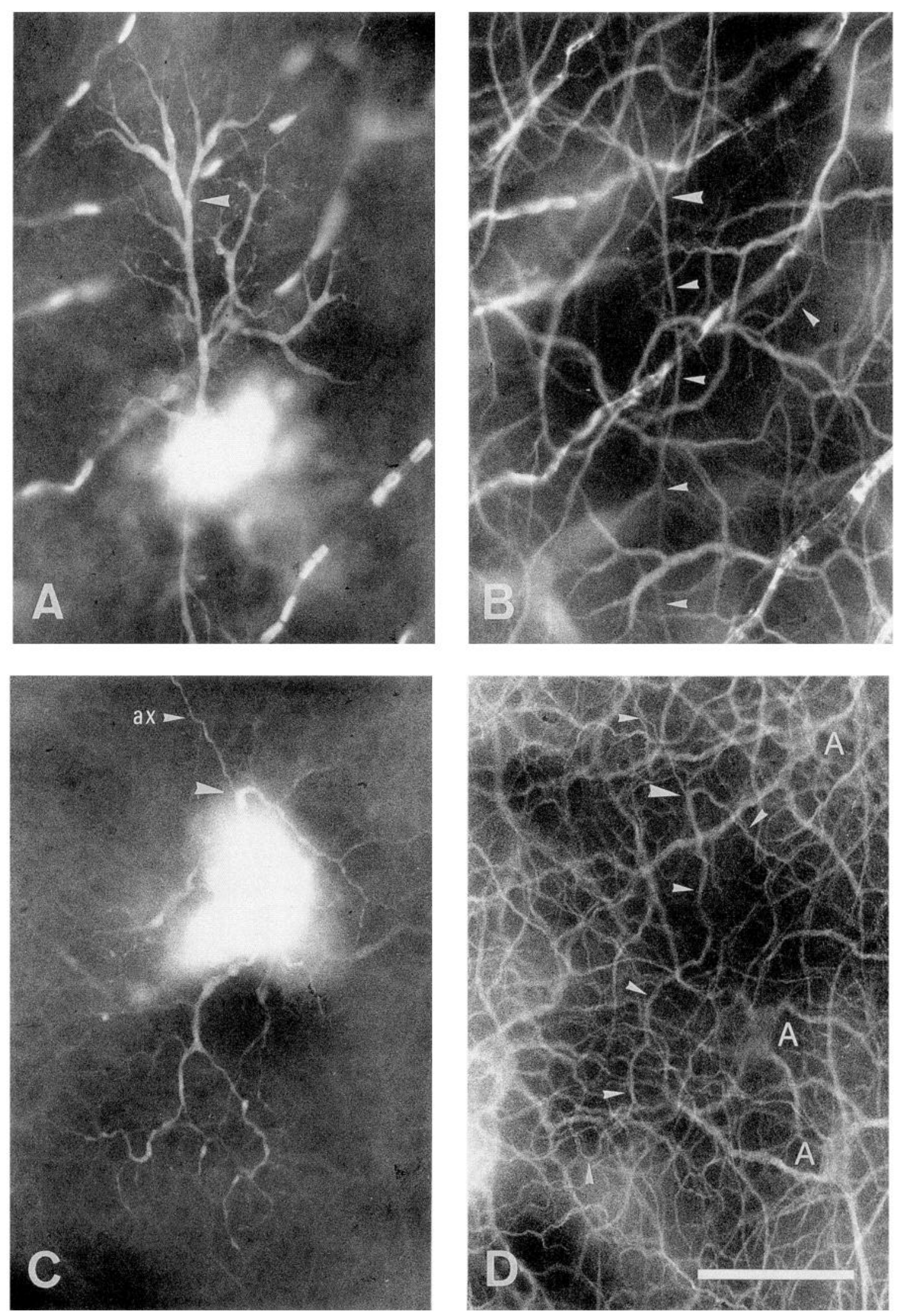
perikarya and dendrites. In rodent B-type horizontal cells all three NF subunits are found in two compartments, the axon and the axon terminal system. Shaw and Weber $(1983,1984)$ had also shown that in several mammalian species, including rat and mouse, NF-L, NF-M, and NF-H antibodies label identical (though unidentified) processes in the outer plexiform layer.

Some of the antibodies used in the present study recognize both phosphorylated and nonphosphorylated forms of the NF subunits, but NE14 and NAP4 only recognize phosphorylated NF subunits (Table 1). Their labeling pattern of rodent horizontal cells does not differ significantly from that of the other antibodies. It can be concluded that rodent B-type axon terminal systems, and guinea pig A-type horizontal cell dendrites and perikarya, contain phosphorylated NF-H. Generally, phosphorylated $\mathrm{NF}_{-} \mathrm{H}$ is mainly found in axons, and neuronal perikarya and dendrites are not labeled by phosphorylation-dependent NF-H antibodies (Stern berger and Sternberger, 1983; Shaw et al., 1986). The different distribution of phosphorylated versus nonphosphorylated subunits in neuronal compartments has been reviewed and discussed by Shaw (1986, 1991), Matus (1988), and Fliegner and Liem (1991). Guinea pig A-type horizontal cells are a case where phosphorylated NF-H is not confined to axonal structures. Nor have the B-type axon terminal systems conventional "axonal" properties. Their synaptic connections with the rods are similar to the B-type dendritic synapses with the cones (Kolb, 1974; Linberg and Fisher, 1988), and the thin axon does not appear to conduct electrical signals (Nelson et al., 1975).

Mouse and gerbil B-type perikarya and dendrites do not contain neurofilaments that are recognized by the antibodies used here. In rat and guinea pig, B-type perikarya and dendrites are faintly labeled by antibody N52, but not by NE14 or any of the other antibodies, suggesting that they contain low amounts of nonphosphorylated NF-H. This is an unexpected finding as electron microscopy did not reveal neurofilaments in cat and rabbit B-type horizontal cells (Fisher and Boycott, 1974). Rabbit B-type dendrites and perikarya, however, also show faint N52 labeling (Löhrke, Brandstätter, and Peichl, unpublished observations). Under the assumption that the antibody does not cross-react with other cellular components, this argues for low levels of nonphosphorylated NF-H in mammalian B-type dendrites and perikarya, which perhaps escape ultrastructural detection or are present in a non-filamentous form.

The distribution of NF subunits within neurons has been studied previously. Initial studies reported a differential distribution of the subunits, but Trojanowski et al. (1985, 1986), using a large set of monoclonal antibodies, found a similar distribution of all three subunits in most NF-containing neurons they studied. They discuss the pertinent literature and argue that apparently different distributions may be explained by a microheterogeneity of NF subunit expression producing different epitopes and corresponding recognition problems for the antibodies. Shaw $(1986,1991)$ also discusses the issue that NF sub- units differ in amino acid sequence between species and may be differentially distributed in neurons. Such caveats also apply to studies on horizontal cells, as apparent with the NF-L subunit that is recognized in all our species by antibody DA2, but only in some by NR4 (Table 1). It may be that rodent B-type dendrites contain additional NF subunits that are not recognized by the present antibodies.

Are neurofilaments required by the architecture of the cytoskeleton in certain types of processes, or by the functional role these processes have? Why do the dendrites of A-type cells, but not of B-type cells, contain the three NF subunits? Why do A-type horizontal cells express neurofilaments in some species (see introductory remarks) but apparently not in others (e.g., human; Kivelä et al., 1986; Straznicky et al., 1992)? Why is there a regional difference of NF expression in guinea pig horizontal cells? The points raised in the present article make the horizontal cells an interesting and suitable assay to study NF biology. Adult mammalian horizontal cells can be dissociated (Sarthy and Lam, 1979; Ueda et al., 1992), and early postnatal mammalian horizontal cells can now be cultured (V. Möckel and H.-D. Hofmann, unpublished observations; S. Löhrke and H.-D. Hofmann, unpublished observations), so their cytological and functional properties can be studied in vitro under defined and experimentally modifiable conditions.

\section{References}

Balkema GW, Pinto LH (1982) Electrophysiology of retinal ganglion cells in the mouse: a study of normally pigmented mouse and a congenic hypopigmentation mutant, pearl. J Neurophysiol 48:968-980.

Bloomfield SA, Miller RF (1982) A physiological and morphological study of the horizontal cell types of the rabbit retina. J Comp Neurol 208:288-303.

Boycott BB, Hopkins JM, Sperling HG (1987) Cone connections of the horizontal cells of the rhesus monkey's retina. Proc R Soc Lond [Biol] 229:345-379.

Dahl D, Bignami A (1991) Neurofilament phosphorylation in the axonless horizontal cells of rat retina. Brain Res 553:163-166.

Dräger UC (1983) Coexistence of neurofilaments and vimentin in a neurone of adult mouse retina. Nature 303:169-172.

Dräger UC (1985) Neurofilaments in retinas of normal mice and mice with hereditary photoreceptor loss. In: Cell and development biology of the eye. Heredity and visual development (Sheffield JB, Hilfer SR, eds), pp 43-62. New York: Springer.

Dräger UC, Edwards DL, Barnstable CJ (1984) Antibodies against filamentous components in discrete cell types of the mouse retina. $J$ Neurosci 4:2025-2042.

Fisher SK, Boycott BB (1974) Synaptic connexions made by horizontal cells within the outer plexiform layer of the retina of the cat and rabbit. Proc R Soc Lond [Biol] 186:317-331.

Fliegner KH, Liem RKH (1991) Cellular and molecular biology of neuronal intermediate filaments. Int Rev Cytol 131:109-167.

Gallego A (1976) Comparative study of the horizontal cells in the vertebrate retina: mammals and birds. In: Neural principles in vision (Zettler F, Weiler R, eds), pp 26-62. Berlin: Springer.

Gallego A (1983) Organization of the outer plexiform layer of the Tetrapoda retina. In: Progress in sensory physiology, Vol 4 (Ottoson $\mathrm{D}$, ed), pp 83-114. Berlin: Springer.

Gallego A (1986) Comparative studies on horizontal cells and a note on microglial cells. Prog Retinal Res 5:165-206.

Figure 4. Horizontal ccll axon terminal systems are NF immunoreactive. Axon terminal systems were injected with LY, and the tissue was then $\mathrm{NF}$ immunostained (antibody $2 \mathrm{~F} 11$ ). $A$, Injected axon terminal system in gerbil, viewed with the LY filter setting. A prominent branch point is marked by a large arrowhead. $B$, Same field viewed with the Texas red filter setting. The NF plexus is revealed and includes the identified axon terminal system (small arrowheads; the large arrowhead marks the branch point of $A$ ). Blood capillaries fluoresce with both filter settings and can be used as landmarks. $C$, Injected axon terminal system in guinea pig. The fine axon (ax) expands into a system of larger-caliber processes (large arrowhead). $D$, Same field with Texas red filter setting. The fine axon and the axon terminal system are NF immunoreactive (arrowheads). The NF plexus in addition contains the A-type cells; three of the somata are marked " $A$." In $A$ and $C$ the injection sites are masked by a large spot of extracellular LY, which does not fluoresce with the Texas red filter setting. Scale bar, $50 \mu \mathrm{m}$. 
Hammang JP, Bohn MC, Messing A (1992) Phenylethanolamine N-methyltransferase (PNMT)-expressing horizontal cells in the rat retina: a study employing double-label immunohistochemistry. J Comp Neurol 316:383-389.

Harris J, Ayyub C, Shaw G (1991) A molecular dissection of the carboxyterminal tails of the major neurofilament subunits NF-M and NF-H. J Neurosci Res 30:47-62.

Kivelä T, Tarkkanen A, Virtanen I (1986) Intermediate filaments in the human retina and retinoblastoma. Invest Ophthalmol Vis Sci 27: 1075-1084.

Kolb H (1.974) The connections between horizontal cells and photoreceptors in the retina of the cat: electron microscopy of Golgi preparations. I Comp Neurol 155:1-14.

Linberg KA, Fisher SK (1988) Ultrastructural evidence that horizontal cell axon terminals are presynaptic in the human retina. J Comp Neurol 268:281-297.

Mangel SC (1991) Analysis of the horizontal cell contribution to the receptive field surround of ganglion cells in the rabbit retina. $J$ Physiol (Lond) 442:211-234.

Mariani AP (1985) Multiaxonal horizontal cells in the retina of the tree shrew, Tupaia glis. J Comp Neurol 233:553-563.

Matus A (1988) Neurofilament protein phosphorylation-where, when and why. Trends Neurosci 11:291-292.

Nelson R, von Lützow A, Kolb H, Gouras P (1975) Horizontal cells in cat retina with independent dendritic systems. Science 189:137139.

Partridge LD, Brown JE (1970) Receptive fjelds of rat retinal ganglion cells. Vision Res 10:455-460.

Peichl L, Buhl EH, Boycott BB (1987) Alpha ganglion cells in the rabbit retina. J Comp Neurol 263:25-41.

Ramón y Cajal S (1893) La rétine des vertébrés. La Cellule 9:119257

Ramón y Cajal S (1908) L'hypothèse de Mr. Apáthy sur la continuité des cellules nerveuses entre elles. Réponse aux objections de cet auteur contre la doctrine neuronale. Anat Anz 33:418-448, 468-493.

Raviola E, Dacheux RF (1983) Variations in structure and response properties of horizontal cells in the retina of the rabbit. Vision Res 23:1221-1227

Sarthy PV, Lam DMK (1979) Isolated cells from a mammalian retina. Brain Res 176:208-212.

Shaw G (1986) Neurofilaments: abundant but mysterious neuronal structures. Bioessays 4:161-166.

Shaw G (1991) Neurofilament proteins. In: The neuronal cytoskeleton (Burgoyne R, ed), pp 185-214. New York: Wiley-Liss.

Shaw $G$, Weber $K$ (1983) The structure and development of the rat retina: an immunofluorescence microscopical study using antibodies specific for intermediate filament proteins. Eur J Cell Biol 30:219232.

Shaw G, Weber K (1984) The intermediate filament complement of the retina: a comparison between different mammalian species. Eur J Cell Biol 33:95-104.

Shaw G, Osborn M, Weber K (1986) Reactivity of a panel of neurofilament antibodies on phosphorylated and dephosphorylated neurofilaments. Eur J Cell Biol 42:1-9.

Silveira LCL, Yamada ES, Picanço-Diniz CW (1989) Displaced horizontal cells and biplexiform horizontal cells in the mammalian retina. Vis Neurosci 3:483-488.

Sterling P, Freed M, Smith RG (1986) Microcircuitry and functional architecture of the cat retina. Trends Neurosci 9:186-192.

Sternberger LA, Sternberger NH (1983) Monoclonal antibodies distinguish phosphorylated and nonphosphorylated forms of neurofilaments in situ. Proc Natl Acad Sci USA 80:6126-6130.

Straznicky C, Vickers JC, Gábriel R, Costa M (1992) A neurofilament protein antibody selectively labels a large ganglion cell type in human retina. Brain Res 582:123-128.

Suzuki H, Pinto LH (1986) Response properties of horizontal cells in the isolated retina of wild-type and pearl mutant mice. J Neurosci $6: 1122-1128$

Tauchi M, Masland RH (1984) The shape and arrangement of the cholinergic neurons in the rabbit retina. Proc R Soc I ond [Biol] 223: 101-119.

Trojanowski JQ, Obrocka MA, Lee VM-Y (1985) Distribution of neurofilament subunits in neurons and neuronal processes. J Histochem Cytochem 33:557-563.

Trojanowski JQ, Walkenstein N, Lee VM-Y (1986) Expression of neurofilament subunits in neurons of the central and peripheral nervous system: an immunohistochemical study with monoclonal antibodies. J Neurosci 6:650-660.

Ueda Y, Kaneko A. Kaneda M (1992) Voltage-dependent ionic currents in solitary horizontal cells isolated from cat retina. J Neurophysiol 68:1143-1150.

Vickers JC, Costa M (1992) The neurofilament triplet is present in distinct subpopulations of neurons in the central nervous system of the guinea pig. Neuroscience 49:73-100

Voigt T (1986) Cholinergic amacrine cells in the rat retina. J Comp Neurol 248:19-35.

Wässle H, Boycott BB (1991) Functional architccturc of the mammalian retina. Physiol Rev 71:447-480.

Wässle H, Peichl L, Boycott BB (1978) Topography of horizontal cells in the retina of the domestic cat. Proc R Soc Lond [Biol] 203:269291

Weber K, Shaw G, Osborn M, Debus E, Geisler N (1983) Neurofilaments, a subclass of intermediate filaments: structure and expression. Cold Spring Harbor Symp Quant Biol 48:717-729.

Yamada ES, Silveira LCL, Coimbra AJF (1992) Topography of A-type horizontal cells in the retina of the capybara. Brazilian $J$ Med Biol Res 25:619-632. 